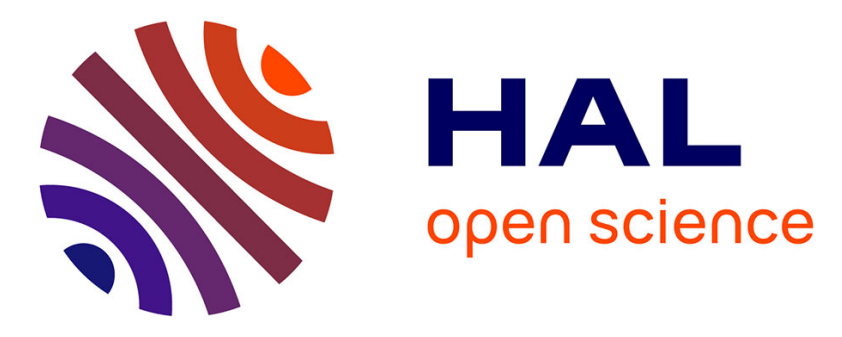

\title{
The dawn of a golden age in mathematical insect sociobiology
}

\author{
Nigel R. Franks, Anna Dornhaus, James A.R. Marshall, François-Xavier \\ Dechaume-Moncharmont
}

\section{- To cite this version:}

Nigel R. Franks, Anna Dornhaus, James A.R. Marshall, François-Xavier Dechaume-Moncharmont. The dawn of a golden age in mathematical insect sociobiology. J. Gadau \& J. Fewell. Organization of Insect Societies: From Genome to Sociocomplexity, Harvard University Press, pp.437-459, 2009. hal-00492310

\section{HAL Id: hal-00492310 https://hal.science/hal-00492310}

Submitted on 20 Feb 2021

HAL is a multi-disciplinary open access archive for the deposit and dissemination of scientific research documents, whether they are published or not. The documents may come from teaching and research institutions in France or abroad, or from public or private research centers.
L'archive ouverte pluridisciplinaire HAL, est destinée au dépôt et à la diffusion de documents scientifiques de niveau recherche, publiés ou non, émanant des établissements d'enseignement et de recherche français ou étrangers, des laboratoires publics ou privés. 


\title{
The Dawn of a Golden Age in Mathematical Insect Sociobiology
}

\author{
NIGEL R. FRANKS, ANNA DORNHAUS, JAMES A. R. \\ MARSHALL, FRANCOIS-XAVIER DECHAUME \\ MONCHARMONT
}

THE TITLE FOR THIS CHAPTER is a prediction. It is bold. It is also arguably overly grand and it may be illusory. History alone will judge if this is the dawn of a golden age in mathematical sociobiology. To be sure, mathematical biology has already seen a number of false dawns. It may appear, for example, that both catastrophe theory and chaos theory each have enjoyed almost all of their 15 minutes of fame. However, it is right and proper that a wave of initial excitement, or indeed, hyperbole, is followed by slower and steadier progress as a field matures.

So what justifies our unbridled optimism? The first answer is demonstrable progress. Self-organization theory and complex systems theory coupled with pioneering experiments have already revolutionized our understanding of organizational aspects of insect societies and even our own societies. Such is the gathering excitement, predictive power, and massing evidence that this endeavor has earned a new epithet: "Sociophysics" or "the physics of society" (Ball 2004; Strogatz 2004). Why sociophysics? Because the philosophy and even some of the principles of statistical mechanics are now being applied in sociobiology to great effect. The central issue in social biology to which mathematical biology is being applied is the question of how societies are organized. In shorthand, how do superorganisms work?

The second answer is that necessity is the mother of invention. The requirement for a mathematical sociobiology was not only predicted by Wilson (1971) but he gave a clear directive that results would come from considering mass action and stochastic effects. These are key aspects of 
statistical mechanics. Modeling is needed because the mechanisms underlying insect societies as complex systems "are neither self-evident nor susceptible of easy proof" (Wilson 1971; emphasis added). Thought experiments are not sufficient to predict the properties of the whole from those of the parts. Their complexity and emergent properties are such that these systems are opaque until they have been disassembled and reassembled and interrogated with a combination of mathematical models and experiments.

In this chapter, we discuss how different modeling techniques can be used to study the functions, mechanisms, and evolution of collective behavior, and how such theoretical approaches can also feed back into em-

pirical research, or into disciplines outside of biology. Finally, we give our-admittedly subjective-recommendations for the future of theoretical sociobiology.

\section{A Typology of Models}

Explanatory models can be split into different categories depending on their aims: teleonomic models (often called optimality models), mechanistic models, and artificial evolution models. Models of the first category aim to illuminate the function or goal of a behavior or other trait (under the assumption that the trait is the result of adaptive evolution, Cuthill 2005). Mechanistic models aim to explain the mechanisms by which a pattern of behavior or other feature is created. Finally, artificial evolution models may help in the understanding of the evolutionary process itself. We discuss each of these types in turn below, along with their benefits and certain cautionary notes.

\section{Teleonomic Models}

Teleonomic models try to portray the function of an aspect of a biological system in an evolutionary context. For example, how could we explain the biased sex-ratio in an ant colony (Bourke and Franks 1995)? The word teleonomy was first used by C. S. Pittendrigh (1958) in order to emphasize that the recognition and description of end-directedness does not carry a commitment to Aristotelian teleology as an efficient causal principle. In other words, an organism may evolve to an optimal state without evolution aiming for that state; a failure to recognize this is at the root of Intelligent 
Design criticisms of evolution. Teleonomic models do not focus on the mechanisms of decision or control of a particular behavior, but rely on the assumption that it was shaped by natural selection and thus looks as if it was optimized for some function relating to reproductive success. Some classical examples of such teleonomic approaches can be found in the optimal foraging literature, which derives optimal behavior from assumptions such as maximization of food intake (Charnov 1976).

Most, but not all, teleonomic models are mathematical in nature; the system under study is (typically) represented by differential equations, which can sometimes be solved analytically. These equations usually represent behavior at a group or population level. In this they are similar to techniques used in physics such as statistical mechanics which applies the techniques of statistics to large numbers of interacting particles to explain the macroscopic properties of populations of such particles. Statistical mechanics is needed when particles, such as molecules, are individually invisible and yet the global properties of the population to which they belong (such as a gas) need to be predicted. Furthermore, the complexity of the resolving interactions is unimaginable even if the initial state and the equations of motion are known. By contrast, classical (or Newtonian) mechanics charts the history of small numbers of visible particles that are relatively large and relatively slow. In insect sociobiology the interacting agents (e.g., workers) can often be marked individually and their movements recorded, but this is not always the case. Individual army ants almost instantly vanish among their nestmates in swarm raids and in many cases of nest construction in ants and termites the individuals disappear underground - but their mass efforts are still of considerable interest and indeed often of awesome complexity and beauty (Franks et al. 1991).

One of the founding fathers of statistical mechanics was the great Victorian physicist James Clerk Maxwell (1831-1879). Maxwell and others drew much of their inspiration for statistical mechanics from contemporary sociologists (Ball 2004). In particular, Maxwell was influenced by Henry Thomas Buckle (1821-1862), a social historian (and author of History of Civilization in England) who argued that societies had underlying regular characteristics notwithstanding the uniqueness and capriciousness of their individual members. For example, Maxwell stated (referring to the study of human behavior): "If we betake ourselves to the statistical method, we do so confessing that we are unable to follow the details of each case, and expecting that the effects of widespread causes, though very different in 
each individual, will produce an average result on the whole nation" (Maxwell 1873a).

Thus, statistical mechanics drew inspiration from studies of human societies and is now being applied to issues in our own societies, such as problems in traffic flow (Helbing and Huberman 1998; Helbing and Treiber 1998). Maxwell also tantalizingly referred to swarms of bees when he was trying to convey the idea of randomly mingling molecules: "If we wish to form a mental representation of what is going on among the molecules in calm air, we cannot do better than observe a swarm of bees, when every individual bee is flying furiously, first in one direction and then in another, while the swarm, as a whole, either remains at rest, or sails slowly through the air" (Maxwell 1873b). Maxwell attributed random movement to the bees in a swarm, likening them to random movement of air particles. Likening insects to molecules persists as a powerful metaphor (Detrain and Deneubourg 2006). However, real honey bees in swarms do not fly about at random (see for example, Couzin et al. 2005). It is a shame that it has taken so long for statistical mechanics to find its way back to one of its natural domains-insect societies.

Example 1: Partial loads in social insect foragers.

Consider foraging in the honey bee. It has been observed that forager bees only partially load at a nectar food source. The optimal time spent in a flower patch of known quality may depend on the cost of flying with a heavy load (Schmid-Hempel, Kacilnek, and Houston 1985). Alternatively, it may be determined by the benefits of returning information about this new food source to the colony (Varju and Núñez 1993), or checking at the colony whether other, superior food sources have been discovered (Dornhaus et al. 2006). Returning to the nest with a full load of nectar from a mediocre food source is very time consuming and could be a suboptimal strategy. Yet flying back quickly could also be a suboptimal strategy if new and better food sources are rarely discovered. Dornhaus et al. (2006) used a mathematical model to analyze the importance of information collected at the nest; because of its mathematical form, it requires just a few parameters.

The simplicity of mathematical models is both their strength and their weakness. Biological sophistication can never be captured fully in a model, but especially population-level models like the one described above 
cannot take individual variability into account, and in general many variables have to be aggregated in very few parameters. For some questions this is appropriate, for others it is not. However, there are other modeling techniques that allow inclusion of more biological detail. For teleonomic questions, two other approaches are also used: evolutionary modeling is used as an optimization method (as opposed to analytical derivation of an optimum as described in the example above), and individual-based models are used to quantify the benefits and costs of certain behaviors under a large number of conditions, thus also making predictions about which behavior tends to give the highest benefits in certain situations.

The aim of teleonomic models is to solve a problem from an engineering or strategic standpoint. For example, what decision rules should lead to the most effective nectar collection? Such an approach relies on the assumption that natural selection shaped the biological system in order to be most effective. If the experimental data deviate from the optimal predictions of the model, this will shed new light on the biological interpretation of the system.

\section{Mechanistic Models}

Mechanistic models attempt to generate and test hypotheses about proximate mechanisms creating a behavior, either at the individual or group level. Understanding the mechanisms underlying group-level social dynamics within a eusocial insect colony is difficult without abstraction tools. A colony of millions of workers, for example, is a quintessential complex system. It is here that individual-based models in particular have had their largest impact: examples of the outstanding success of such approaches in social insect studies can be found in the application of self-organization theory. Each mechanistic model assumes a particular mechanism, and predicts how the system will behave under this assumption. The predictions of several potential mechanisms can thus be compared; if any of these predict system behavior incorrectly, the corresponding mechanism can be rejected.

Example 2: The blind leading the blind and the self-organization of army ant swarm raids.

Self-organization can be defined as a process that creates a pattern at the global level (e.g., the colony level) through multiple interactions among 
the components (e.g., the workers). The components interact through local, often simple, rules that do not explicitly code for the global pattern (see Camazine et al. 2001).

The global patterns, whose generation we will examine, are the swarm raids of the New World army ant Eciton burchellii (Figure 19.1). Such swarm raids are massive compared to the size of the individuals that create them. An E. burchellii raid can be 20 meters wide and 200 meters long and employ 200,000 individuals (Franks 1989). Furthermore, an overview of the swarm raid pattern is not available to individual workers in Eciton be-

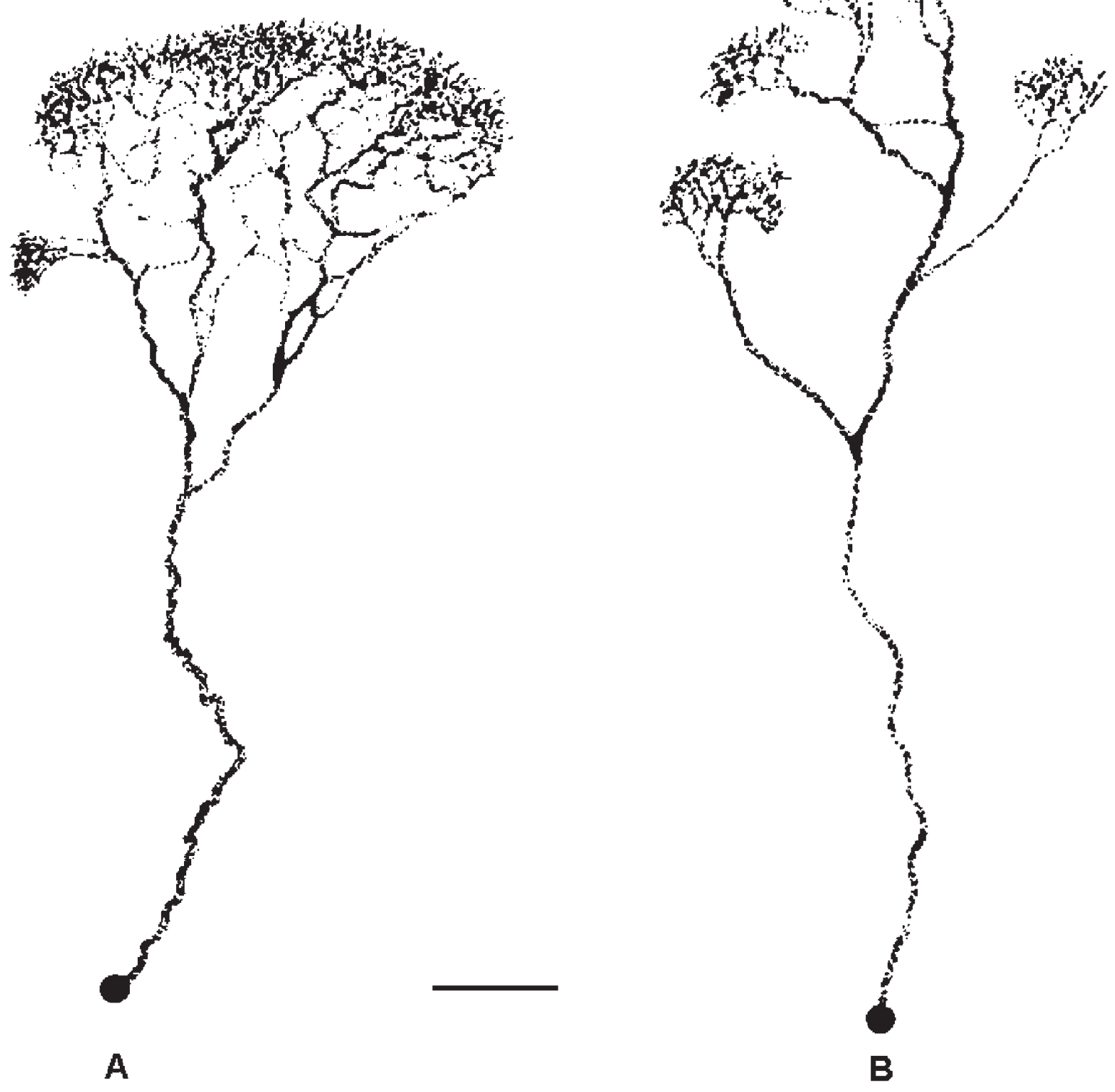

Figure 19.1. The typical pattern of swarm raiding by (A) Eciton burchellii and (B) Eciton rapax. The scale bar represents 5m. Redrawn from Burton and Franks, 1985, with the kind permission of Blackwell Publishing; (A) originally redrawn from Rettenmeyer (1963). 

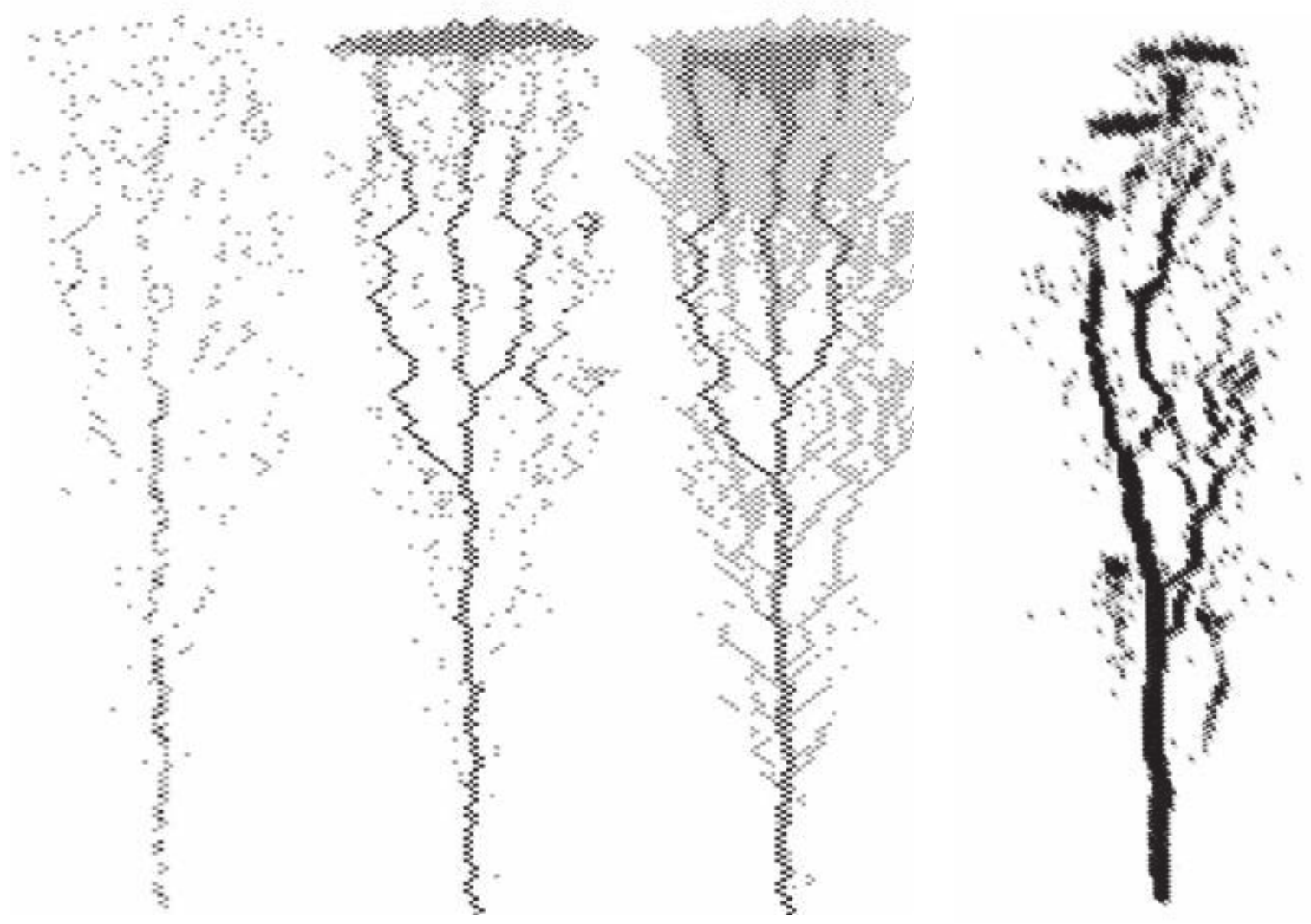

Figure 19.2 A cellular automata model of the generation of Eciton swarm raids. The first three illustrations are overlays of the same model raid for Eciton burchellii. From left to right the figure shows the density of returning ants; the density of all ants, and the density of pheromone trails. The darker the grey level the greater the density. The fourth and right-most illustration shows the density of all ants for the model re-run for a prey distribution typical of that encountered by an Eciton rapax raid. These illustrations were generated de novo by rerunning the computer simulation model described in Deneubourg et al. 1989 (see also Franks et al. 1991).

cause they have extremely rudimentary sight (Schneirla 1971; Franks 1989; Gotwald 1995). A computer simulation model of the self-organization of an army ant raid (see Figure 19.2) used the following simple set of rules (Deneubourg et al. 1989).

1. Leading: Each and every ant lays a followable pheromone trail wherever it goes (unless it is on a trail fully saturated with pheromone).

2. Randomness: If an ant is in virgin terrain it randomly goes left or right (at every bifurcation point in the computer simulation lattice).

3. Following: If an ant is in terrain already traversed by a nestmate it is most likely to follow the pheromone trail laid by that nestmate. (E.g., it 
has a higher probability of turning left than right if the previous ant turned left rather than right, or vice versa, and marked that path.) Because army ants follow one another's trails and reinforce them, trails can get stronger and stronger.

4. Speeding: Up to a limit, the more trail pheromone present the faster each individual will run.

5. Crowding: An ant will not, however, enter an area that is already over-crowded by its nestmates.

6. Returning: Ants only return home when they have encountered prey items. Returning ants obey the same rules for following the pheromone trail as outgoing ants, but they lay more trail pheromone than outgoing ants.

7. Flow: A constant number of ants leave the nest per unit time.

These seven golden rules are sufficient for the blind to lead the blind in the creation of a swarm raid of dazzling complexity and sophistication. It is imperative to note, however, that these seven qualitative rules must be executed in good quantitative agreement with the characteristics of the real army ants. The rate at which individual workers move matters; the rates of deposition and evaporation of trail pheromones matter; and the relative rates of trail-laying by outward bound and returning ants matter (Franks et al. 1991). All these quantitative variables have been established by studying experimentally the movements of $E$. burchellii workers and they have been incorporated into the model (Figure 19.2). That is, both the qualitative and quantitative assumptions of the model have been verified. Certain predictions of this modeling have also been tested (Franks et al. 1991).

The single most intriguing prediction of this model is that swarm raids have an active architecture. These are event-driven systems. The precise pattern of a raid depends on the distribution of prey encountered. Indeed, when the model is run with no prey and hence no returning ants (rule 6), the anastamosing series of columns behind the raid front is absent and a raid consists only of a broad swarm front and a principle trail. Furthermore, if prey are in large clumps that are few and far between, the model predicts that a swarm raid may break up into divergent sub-swarms. This occurs because strong return traffic flows from two (or more) directions and the outgoing ants part company. Such a raid pattern consisting of subswarms is seen in E. rapax (Burton and Franks 1985), a close relative of $E$. burchellii, which is a specialist predator of other social insect nests and 
thus encounters large clumps of prey that are few and far between (Figure 19.2b). This prediction has been tested by presenting the normally cohesive swarm raids of $E$. burchellii with large clumps of prey that are few and far between. The result was that E. burchellii adopted a swarm raid pattern similar to that of E. rapax (Franks et al. 1991).

\section{Evolutionary Models and Alternative Worlds}

In constructing a model of a biological system, whether an organism or a society, we need not limit ourselves to the representation of that which currently exists. Invaluable as models of existing systems are, it can be equally interesting and instructive to model that which does not exist, but may have or indeed once did. In doing so we begin to touch on a fundamental question of the contingency of evolution; if the tape of evolution were replayed, would the outcome be the same (Gould 1989)? Considering evolutionary alternatives in terms of relative effectiveness for a given task might help illuminate whether a feature evolved as it did due to a direct fitness advantage, or whether evolutionary or physical constraints may have been involved. Considering evolutionary alternatives in a sequence may also allow us to recreate plausible simulations of real evolutionary events in a species, genus, or even phylum. Of course, for some, this approach may seem problematic or even misguided due to the lack of data required for rigorous validation. A converse viewpoint would be that such models might enable us to explore the consequences of theories in the absence of empirical data by acting as extended "opaque thought experiments" in the sense of Di Paolo, Noble, and Bullock (2000).

There is, however, an even more radical viewpoint on evolutionary models: they can be alternative worlds. That is, computer models may be actual instantiations of a different, noncarbon-based form of life, rather than mere simulacra. Under this view these models act as sources of data to inform our theorizing about the nature of life and its attendant processes of ontogeny, phylogeny, and so forth. Such a viewpoint is exemplified by Ray's work with digital organisms (1994) or Bedau's “emergent thought experiment" approach to computer modeling (1999). These issues have been recently summarized more thoroughly elsewhere (Marshall and Franks 2007); here we shall limit ourselves to considering examples of modeling evolutionary alternatives in a little more detail. 
More boldly, if one could measure the effectiveness of different alternative realizations of the same adaptive feature, and know which realizations were present at various points in evolutionary history, one would be faced with the tantalizing prospect of being able to reproduce a plausible evolutionary history. Some work in this area has already been carried out, such as Niklas' (1999) work on plant morphospaces. Using a simple generative plant model that can give rise to a variety of morphologies from varying a small number of parameters, and equipped with a fitness function that evaluates morphologies in terms of criteria such as light absorption, mechanical stability, and so on, it is possible to construct "adaptive walks" through the morphospace of possible plant forms via a simple local search of similar forms of higher fitness. Niklas uses such a model to consider what the effects of increasing the number of morphological optimality criteria are on the fitness landscapes and the adaptive walks over them. However, if the starting point for the adaptive walk could be determined by reference to a fossil plant for example, would it not be intriguing if such a simple model could recreate the evolution from this ancestral form to the modern day form, via various intermediate forms observed in the fossil record?

For sociobiology, reconstructing evolutionary histories may be more problematic, as behavior is somewhat difficult to fossilize, and those fossils that do result from behavior may require much interpretation (e.g. Miller, 2003). We need not despair however, as we can look to more "primitive" behaviors, in other species, that are related to our species of interest. Also, we could generate the missing origin of the adaptive walk through our own hypothesizing; for example, one plausible sequence of adaptations leading to the evolution of the collective decision-making mechanism employed by Temnothorax albipennis during house-hunting has been proposed by Pratt et al. (2002, 2005; Pratt, this volume). Such hypotheses may be rescued from being labeled as "just-so" stories if a suitable computer model could demonstrate plausibly the adaptive value of each link in the proposed evolutionary chain.

\section{Classic Problems with Modeling Approaches}

The two examples given above, foraging by honey bees and the self-organization of army ant raids, exemplify the value of supplementing empirical with theoretical studies. Nevertheless, models are only as good as their as- 
sumptions. Indeed, when they rely on large sets of untested assumptions, they have to be handled with care and their predictions regarded with extreme caution, or better, unrestrained skepticism. Many models, whether individual-based or even based on a modest-sized system of differential equations, cannot be studied analytically, so they have to be studied through numerical resolution. The modification of a single parameter may have incredibly dramatic consequences for the general predictions of a model. This is why theoreticians using complex mechanistic models have a duty to perform long and tedious sensitivity analyses. It is becoming clear that simulation models are a new kind of experimental system (or more accurately, the use of simulation falls somewhere between traditional tractable formulation and experimental system). Simulations are properly explored using the same experimental (experimental design) and statistical techniques (visualization, statistics, data mining) that are used to explore real-world systems. If a modeler wants to discover functional dependencies, then a barrage of trials must also be run to examine predictions across a wide range of parameters.

Another pitfall to be avoided is the illusion that such theoretical approaches can proceed without being directed by strong biological questions. Certain models, for example, claim to be open-minded and to be question-free at their inception. Hogeweg and Hesper (1990) made exactly this kind of error while reviewing strong points of individual-based models. They explicitly referred to what they call "self-structuring and non-goal directed models ... [Individual-based models] can be non-goaloriented models, i.e. one does not have to determine in advance what features will be studied."

Biologists should never just naïvely hope that an interesting property will emerge from their model. The hope pinned to individual-based models was that, once the individuals had been specified in a model, the collective level consequences would emerge naturally. Similarly, a lot of complex simulations are built without any hierarchical structure. Because there appears to be no need to think carefully about the assumptions or the parameters, one might be tempted to consider that all the parameters have the same level of accuracy or importance. Such a view is downright dangerous, not least because the effects of important parameters can be diluted among a jumble of other effects.

For example, most mechanistic models require a much more detailed understanding of variability and stochasticity, both through differences 
between individuals and a changing environment, than population-level models. The study of inter-individual differences has gained popularity, maybe because of that; it has revealed that individuals can differ substantially in their sensory, cognitive, and motor abilities (Scheiner, Erber and Page 1999; Scheiner and Erber, this volume), as well as differing in their behavioral responses to the same stimuli (Weidenmüller 2004; Chittka et al. 2003). This is an important aspect to consider if discussing, for example, task allocation in social insect colonies. Similarly, it is becoming clear that the physical environment, and its variability, may play a big role in creating organization. It can serve as a seed or template for structure, or it can be used as a medium not just for information transmission but also information storage (stigmergy) (Detrain and Deneubourg 2002; Dornhaus and Chittka 2005). Often the dynamics and the evolution of strategies used by social insects can only be understood by considering the type of environment and the variability to which they are exposed (Dornhaus and Chittka 2004b). The recognition of the importance of the environment should lead to new experimental studies that focus on quantifying environmental parameters and how they change, as well as the social insect behaviors themselves.

Earlier, we alluded to the term sociophysics and the label "the physics of society," and we think this term can be problematic. The problem arises if people imagine that societies can be reduced purely to physics. For example, Camazine et al. (2001) put extreme emphasis on the crucial point that self-organization is not an alternative explanation to natural selection for complexity in biology. Nevertheless, when their book was reviewed in Nature, a biophysicist repeated this error (Ben-Jacob 2002). Unfortunately, we think it is likely to be repeated again and again because some of the most dramatic recent demonstrations of self-organization in biology have experimentally accentuated the physics of these systems. Consider three recent examples from studies of ants. First, Lasius niger does not habitually forage on bridges (Dussutour et al. 2004). Second, Linepithema humile workers probably very rarely accumulate at the end of twigs and then drip-off like a chaotically leaking tap (Bonabeau et al. 1998; Theraulaz et al. 2001). Third, Messor sancta in nature will never encounter so many dead bodies outside their nest, in a circular arena, that they will exhibit Turing morphogenesis-producing cemeteries in regularly spaced clusters (Theraulaz 2000). Nevertheless, even though all these studies arguably excessively turn-up-the heat to accentuate the "signal to noise 
ratio," they are valuable in that they reveal the biological principles that may have an important role in these systems — only to a much more subtle degree in the natural world. As is the case with all laboratory studies of behavior, ideally they should be followed up with fieldwork whenever this is possible. Of course, the purpose of some of these experiments may not have been the study of (natural) ant behavior, but the study of collective behavior of a complex system where one tests, for example, how different patterns can be created. This can be a worthy goal in itself, especially if the resulting insights can be used successfully to design artificial systems that employ logically similar processes to generate useful patterns and procedures. It is important to note that none of these findings show that biology reduces to physics. Biology is unique among the sciences because it is the domain of evolution by natural selection, thus it is underpinned by physics and chemistry but does not reduce to them.

\section{New Topics in (Empirical) Insect Sociobiology}

The use of a variety of modeling approaches has made sociobiology a truly interdisciplinary effort. Once such connections between disciplines are established, methods and ideas can be exchanged in both directions. This has inspired and helped the empirical study of social insects as well. Biologists are now exploring new questions experimentally, inspired by theoretical advances in other fields. Networks theory, with the now famous "small world effects," was established in mathematics and sociology, but is now being applied to the pattern of interactions in social groups of animals (Fewell 2003; Couzin et al. 2005) as well as that of ecological interactions (Memmott 1999; Memmott, Waser, and Price 2004). The realization in mathematics and physics that positive feedback systems can lead to pattern formation has prompted biologists to examine feedback loops, for example, in recruitment (Beekman, Sumpter, and Ratnieks 2001); traffic flow (Couzin and Franks 2002), aggregation behavior (Jeanson et al. 2004; Jeanson and Deneubourg, this volume), and spatial structure (Theraulaz et al. 2002; Bonabeau et al. 1998). Researchers in economics and epidemiology have developed methods of analyzing the spread of ideas and diseases, looking for patterns of information flow in heterogeneous populations (Britton et al. 2002; Feffermann and Traniello this volume) and discovering how some disappear while others spread rapidly. Similarly, social insect researchers have realized that information is not evenly distributed in an 
insect colony and have started to study ways of information flow (e.g., Seeley 1998; Dornhaus and Chittka 2004a). They, in turn, found bifurcation and collective decision making involving minimal colony sizes and quorum thresholds reminiscent of critical masses (Franks et al. 2002; Beckers et al. 1989; Anderson and McShea 2001; Seeley and Visscher 2004). Others have demonstrated how decision making in a social insect colony may function in a similar manner to neural circuits in the primate brain, and thus similarly achieve optimal decision making (Marshall et al., submitted). More parallels are sure to be found between such systems, and rather than reinventing wheels separately, researchers would do well to explore the use of techniques and results already established for similar systems in other fields.

Nevertheless, interdisciplinary research has its difficulties, not just because one has to admit ignorance and be prepared to learn about a new system. It also often means adjusting to the different traditions of research and communication in another field. It is therefore not surprising that a certain reluctance has to be overcome before a common language is found and ideas are fruitfully exchanged between disciplines. To some degree, the complexity of the models used in theoretical sociobiology has forced biologists to interact with mathematicians and computer scientists, and the complexity of many man-made systems has led computer scientists and engineers to look for problem-solving strategies in (equally complex) biological systems. The emergence of pattern from collective activity-selforganization-has thus become a buzz-word in several disciplines. Social insect research, neuroscience, physics, sociology, computer science, and other fields have discovered the similarities in the processes underlying pattern formation in their systems, which was only possible after they had started creating a common language to talk about them (Camazine et al. 2001; Ball 1999). This interaction has introduced not only new ideas to biology, and particularly social insect science, but also new tools, such as individual-based simulations and other mathematical and computational techniques. A growing number of studies now look at mechanisms of how collective pattern is created (e.g., Bonabeau et al. 1998; Franks and Deneubourg 1997; Camazine et al. 2001; Millor et al. 1999; Roces 2002; Sendova-Franks and Franks 1999; Watmough and Camazine 1995), in addition to studying why animals collaborate in the first place. The latter involves weighing benefits against costs and thus often mathematical models; the former, however, is usually too complex to be solved analyti- 
cally and is only possible by the rise in the power of available computational tools.

New modeling techniques can open up new areas to be studied, and thereby inspire new experiments. In fact, the more interesting results of modeling studies are not those that confirm old hypotheses; they are those results that show us that we do not actually understand why and how things happen the way they do. This, in an ideal world, should lead to new and experimental ways of approaching the system under study, but the temptation is great to bend and "correct" the model in such a way that it conforms to previous hypotheses. It is vital that we let our views of how social insect colonies work be challenged by results from new modeling studies; at the same time, all models should suggest ways to test any new hypotheses in the real world.

Attempting to build a model of collective behavior usually leads to the realization of how much we still do not know. Too often, the interaction is a one-way street: models use experimentally collected data, but predictions of models are then not tested on a real-world system. We think that this is one of the big opportunities, but also challenges, opened up by using models: to close the gap, to help identify and lead to the collection of missing data, and to test new hypotheses and predictions from modeling studies experimentally. However, it is also important to realize that models can lead not only to new experiments but also to important new questions.

\section{Repaying the Favor: Feedback from Biology into Other Disciplines}

Thus far, we have sought to demonstrate the contribution that mathematical models and computers have made to the development of insect sociobiology. In return, the study of social insects has made contributions of its own to computer science, mathematics, and related disciplines. Computer scientists are increasingly realizing that social insects have evolved solutions to some difficult problems, such as foraging; problems that are similar in many respects to those encountered by computer scientists. In the twenty-first century the ubiquity of computers and networks such as the Internet has created a host of problems in which a global, accurate picture of the entire problem is not available for the planning of a solution. Rather, approaches to these problems must try to optimize a solution using only local and uncertain information. It is precisely these constraints that social 
insects work under; consider the example of foraging behavior in social insects, in which individual insects only have access to local information (the food sources they discover or are recruited to by other scouts) which is uncertain (food sources can fluctuate in quality, appear or disappear, etc.). For such problems the collective behaviors of social insects may provide inspiration for robust and efficient solutions. One example is the application of an algorithm based on pheromone-based foraging in ants to the routing of connections in a telecoms network (Dorigo and Stützle 2004). In the ants, shorter paths to a food source receive more ant traffic and hence more pheromone, and positive feedback for those shorter paths occurs. However, if new and better paths become available or old high-use ones are blocked, the colony is often able to adapt. Other social insect behaviors may be applicable to engineering problems; the house-hunting behavior of Temnothorax albipennis, for example, has been studied with reference to decentralized control problems such as process migration in computer networks (Marshall et al. 2006).

Even in cases where a global view of the problem is available, there is a significant class of problems in computer science and mathematics that are combinatorial; that is, there are too many possible solutions to evaluate all the alternatives exhaustively. One famous example is a kind of shortest path problem known as the Traveling Salesman Problem, in which the shortest possible tour visiting all the cities in a country exactly once must be discovered. Heuristic approaches for solving such problems are required, and here again the pheromone-based foraging behavior of ants has provided inspiration. By allowing a simulated ant colony to "forage" repeatedly for the shortest tour around the cities, important components of the tour are found to be those that repeatedly are heavily marked with virtual pheromone, and these components may be combined into a single good quality solution (Bonabeau, Dorigo, and Theraulaz 1999). Social insect-inspired engineering solutions have been derived from spatial sorting (Lumer 1994) or task allocation (Bonabeau, Dorigo, and Theraulaz 1999), and are used in job-shop scheduling (Cicirello 2004), software 'agents' (Parunak 1997; Weiss 1999), optimization of communication networks (DiCaro and Dorigo 1998), and collective robotics (e.g., for planetary exploration; Brooks and Flynn 1989; Krieger, Billeter, and Keller 2000). Moreover, computer science and mathematics are not the only disciplines to benefit from insights into the collective behavior of social insects; such disparate fields as corporate organization and sociology have 
also taken inspiration from social insect organization (Costa 2002; Parunak 1997). Of course, interest in what lessons social insects might hold for the organization of human affairs has a long and venerable history: "It is true that certain living creatures, as bees and ants, live sociably one with another (which are therefore by Aristotle numbered amongst political creatures) ... and man may desire to know why mankind cannot do the same." (Hobbes 1651).

\section{Recommendations for the New Generation Mathematical Sociobiologist}

As the French mathematician Henri Poincaré (1905) said, "Science is built of facts as a house is built of stones; but an accumulation of facts is no more science than a heap of stones is a house." If biology is to be more than just "stamp collecting" (or stone heaping), and more like physics, then theory is essential. In fact, recent advances in the mathematical and computational sciences have brought theory to the fore in biology. However, Jacob (1970) was rather overstating the matter when he said, "One doesn't study life in laboratories these days." Rather, we feel that while modeling has tremendous contributions to make to the development of biological understanding, biological experimentation and validation should always be the final arbiter (see also Bray 2001; May 2004).

We believe that the quality of a modeling study is directly related to how clearly the questions, the assumptions, and the hypotheses are laid out, and how well the method used can distinguish between these hypotheses. Progress is only made when questions are answered. Merely achieving a similarity of certain model results with empirically observed ones does not guarantee that the underlying mechanisms are the same (Bonabeau and Theraulaz 1994). The scientific approach of devising hypotheses and attempting to falsify them is bread and butter to any empirical biologist, but is not necessarily part of a mathematician's or computer scientist's daily work. Particularly with stochastic models, the same techniques of multiple sampling and statistical analysis have to be used as with an empirical study. This also is needed to check that any model results apply to the biologically relevant parameter values.

Simple models are usually more illuminating than complex ones. Estimating parameter values used in numerical models always entails the necessity of performing a sensitivity analysis. If many parameters have to be 
estimated, a sensitivity analysis can become cumbersome-and this is one of the most important reasons for preferring a simple model to a complex one. When a model is designed, the feasibility of analyzing it should be considered at the outset. Further, in complex models the underlying assumptions are often hard to specify. However, understanding how certain assumptions lead to the observed results is key to the explanatory value of a model.

Lastly, in order to make an impact on a field that is mostly empirical, modelers should aim to communicate their results to empiricists. This can be helped by clearly stating how model results follow from particular assumptions. Models should make testable predictions and such tests should be spelled out explicitly in a modeling study.

What are the hallmarks of good modeling studies? (1) They should answer a biologically relevant question by spelling out hypotheses and disproving some of them. (2) They should show that the results apply to biologically relevant parameter values, and are independent of some variation in parameter estimates. (3) They should clearly indicate which assumptions led to the results. (4) Last, but not least, they should suggest empirical ways of testing the conclusions of the model. Models that meet this "goldstandard" should not fail to make a substantial impact in this field.

In sum, as insect sociobiologists we have an unrivaled opportunity to observe our study organizations part and parcel. We can then employ recent developments in statistical physics, its sister disciplines of complexity theory and self-organization theory, and the new realm of individual-based modeling to generate testable hypotheses. And we can evaluate and test these ideas through close-coupled iterated loops of progressive modeling and experimentation. The future is indeed bright for insect sociobiology.

\section{Acknowledgments}

We wish to thank BBSRC (EF19832) and EPSRC (GR/S78674/01) and the DFG (German Science Foundation, Emmy Nöther Fellowship to A.D.) for funding.

\section{Literature Cited}

Anderson, C., and D. W. McShea. 2001. "Individual vs. social complexity, with particular reference to ant colonies.” Biological Reviews 76: 211-237. 
Ball, P. 1999. The self-made tapestry. Oxford: Oxford University Press. 2004. Critical mass: How one thing leads to another. London: William Heinemann.

Beckers, R., S. Goss, J. L. Deneubourg, and J. M. Pasteels. 1989. "Colony size, communication and ant foraging strategy." Psyche 96: 239-256

Bedau, M. A. 1999. "Can unrealistic computer models illuminate theoretical biology?” In A. S. Wu, ed., Proceedings of the 1999 genetic and evolutionary computation conference workshop programme, 20-23. San Francisco: Morgan Kaufmann.

Beekman, M., D. Sumpter, and F. Ratnieks. 2001. "Phase transition between disordered and ordered foraging in Pharaoh's ants." Proceedings of the National Academy of Sciences USA 98: 9703-9704.

Ben-Jacob, E. 2002. "When order comes naturally." Nature 415: 370.

Bonabeau, E., M. Dorigo, and G. Theraulaz. 1999. Swarm intelligence: From natural to artificial systems. New York: Oxford University Press.

Bonabeau, E., G. Theraulaz, J.-L. Deneubourg, N. R. Franks, O. Rafelsberger, J. L. Joly, and S. Blanco. 1998. "A model for the emergence of pillars, walls and royal chambers in termite nests." Philosophical Transactions of the Royal Society of London: Biological Sciences 353: 1561-1576.

Bonabeau, E., and G. Theraulaz. 1994. "Why do we need artificial life?" Artificial Life 1: 303-325.

Bonabeau, E., G. Theraulaz, J.-L. Deneubourg, A. Lioni, F. Libert, C. Sauwens, and L. Passera. 1998. "Dripping faucet with ants." Physical Review E Volume 57: 5904-5907.

Bourke, A. F. G., and N. R. Franks. 1995. Social evolution in ants. Princeton: Princeton University Press.

Bray, D. 2001. "Reasoning for results." Nature 412: 863.

Brooks, R. A., and A. M. Flynn. 1989. "Fast, cheap, and out of control: A robot invasion of the solar system. Journal of the British Interplanetary Society 20: 478-485.

Britton, N. F., N. R. Franks, S. C. Pratt, and T. D. Seeley. 2002. "Deciding on a new home: How do honeybees agree?" Proceedings of the Royal Society B 269: 1383-1388.

Burton, J. L., and N. R. Franks. 1985. "The foraging ecology of the army ant Eciton rapax: An ergonomic enigma?” Ecological Entomology 10: $131-141$.

Camazine, S., J.-L. Deneubourg, N. R. Franks, J. Sneyd, G. Theraulaz, and E. Bonabeau. 2001. Self-organization in biological systems. Princeton: Princeton University Press.

Charnov, E. L. 1976. "Optimal foraging, the marginal value theorem." Theoretical Population Biology 9: 129-136. 
Chittka, L., A. G. Dyer, F. Bock, and A. Dornhaus. 2003. "Bees trade off foraging speed for accuracy." Nature 424: 388.

Cicirello, S. and S. F. Smith 2004. "Wasp-like agents for distributed factory coordination." Journal of Autonomous Agents and Multi-Agent Systems 8: 237-266.

Costa, J. T. 2002. "Scale models? What insect societies teach us about ourselves.” Proceedings of the American Philosophical Society 146: 170-180.

Couzin, I. D., and N. R. Franks. 2002. "Self-organized lane formation and optimized traffic flow in army ants." Proceedings of the Royal Society B 270: 139-146.

Couzin, I. D., J. Krause, N. R. Franks, and S. A. Levin. 2005. "Effective leadership and decision-making in animal groups on the move." Nature 433: 513-516.

Cuthill, I. C. 2005. "The study of function in behavioural ecology. Animal Biology 55: 399-417.

Deneubourg, J. L., S. Goss, N. R. Franks, and J. M. Pasteels. 1989. “The blind leading the blind: Modeling chemically mediated army ant raid patterns." Journal of Insect Behavior 2: 719-725.

Detrain, C., and J.-L. Deneubourg. 2002. "Complexity of environment and parsimony of decision rules in insect societies." The Biological Bulletin 202: 268-274.

- 2006. "Self-organized structures in a superorganism: Do ants "behave" like molecules?” Physics of Life Review 3: 162-187.

DiCaro, G., and M. Dorigo. 1998. “AntNet: Distributed stigmergic control for communications networks." Journal of Artificial Intelligence Research 9: 317-365.

Di Paolo, E. A., J. Noble, and S. Bullock. 2000. "Simulation models as opaque thought experiments." In M. A. Bedau, Bedau MA.; Snyder E and N. H. Packard, eds., Proceedings of the Seventh International Conference on Artificial Life, 497-506. Cambridge: MIT Press.

Dorigo, M., and T. Stützle. 2004. Ant colony optimization. Cambridge: MIT Press.

Dornhaus, A., and L. Chittka. 2004a. "Information flow and regulation of foraging activity in bumble bees.” Apidologie 35: 183-192.

- 2004b. "Why do honey bees dance?" Behavioral Ecology and Sociobiology 55: 395-401.

- 2005. "Bumble bees (Bombus terrestris) store both food and information in honeypots." Behavioral Ecology Behavioral Ecology 16: 661-666.

Dornhaus, A., F. Klügl, C. Oechslein, F. Puppe, and L. Chittka. 2006. Benefits of recruitment in honey bees: ecology and colony size." Behavioral Ecology 17: 336-344. 
Dussutour, A., V. Fourcassié, D. Helbing, and J.-L. Deneubourg. 2004. "Optimal traffic organization in ants under crowded conditions." Nature 428: 70-73.

Fewell J. H. 2003. “Social insect networks.” Science 301: 1867-1870.

Franks, N. R. 1989. “Army ants: A collective intelligence.” American Scientist 77: $138-145$.

Franks, N. R., and J.-L. Deneubourg. 1997. "Self-organizing nest construction in ants: individual worker behaviour and the nest's dynamics." Animal Behaviour 54: 779-796.

Franks, N. R., A. Dornhaus, J. P. Fitzsimmons, and M. Stevens. 2003. "Speed vs. accuracy in collective decision making." Proceedings of the Royal Society of London Series B 270: 2457-2463.

Franks, N. R., S. C. Pratt, E. Mallon, N. Britton, and D. Sumpter. 2002. "Information flow, opinion-polling and collective intelligence in househunting social insects." Philosophical Transactionsof the Royal Society: Biological Sciences 357: 1567-1583.

Franks, N. R., A. B. Sendova-Franks, J. Simmons, and M. Mogie. 1999. "Convergent evolution, superefficient teams and tempo in Old and New World army ants." Proceedings of the Royal Society of London B 266: 1697-1701.

Franks, N. R., N. Gomez, S. Goss, and J.-L. Deneubourg. 1991. “The blind leading the blind in army ant raid patterns: Testing a model of self-organization." Journal of Insect Behavior 4: 583-607.

Gotwald, W. H. 1995. Army ants: The biology of social predation. Ithaca: Cornell University Press.

Gould, S. J. 1989. Wonderful life: The Burgess shale and the nature of history. New York: Norton.

Helbing, D., and B. A. Huberman. 1998. "Coherent moving states in highway traffic." Nature 396: 738-740.

Helbing, D., and M. Treiber. 1998. "Traffic theory-Jams, waves and clusters." Science 282: 2001-2003.

Hobbes, T. 1651/1985. Leviathan. London: Penguin.

Hogeweg, P., and B. Hesper. 1990. "Individual-oriented modelling in ecology." Mathematical and Computer Modelling 13: 83-90.

Jacob, F. 1970. La logique du vivant. Paris: Gallimard.

Jeanson, R., J.-L. Deneubourg, A. Grimal, and G. Theraulaz. 2004.

"Modulation of individual behavior and collective decision-making during aggregation site selection by the ant Messor barbarus." Behavioral Ecology and Sociobiology 55: 388-394.

Krieger, M. J. B., J.-B. Billeter, and L. Keller. 2000. “Ant-like task allocation and recruitment in cooperative robots.” Nature 406: 992-995. 
Lumer, F. 1994. "Diversity and adaptation in populations of clustering ants." From Animals to Animats 3: Proceedings of the 3rd International Conference on Simulation of Adaptive Behavior, 501-508.

Marshall, J. A. R., A. Dornhaus, N. R. Franks, and T. Kovacs. 2006. "Noise, cost and speed-accuracy trade-offs: Decision making in a decentralized system." Journal of the Royal Society: Interface 3: 243-254.

Marshall, J. A. R., and N. R. Franks. 2007. "Whys and wherefores of computer modelling in behavioural biology.” In Laubichler M.D Müller, G.B. eds., Modeling biology-Structures, behavior, evolution. Cambridge: MIT Press.

Maxwell, J. C. 1873a. "Science and free will.” In L. Campbell and W. Garnett, eds., The life of James Clerk Maxwell, 438-439. London: Macmillan.

_. 1873b. "Molecules [from Nature, Vol. 8]." In W. D. Niven, ed., The scientific papers of James Clerk Maxwell, Vol II. Cambridge: Cambridge University Press.

May, R. M. 2004. "Uses and abuses of mathematics in biology." Science 303: 790-793.

Memmott, J. 1999. “The structure of a plant-pollinator food web.” Ecology Letters 2: 276-280.

Memmott, J., N. Waser, and M. Price. 2004. "Tolerance of pollination networks to species extinctions." Proceedings of the Royal Society B 271: 2605-2611.

Miller, W. III. (ed). 2003. "New interpretations of complex trace fossils." Palaeogeography, Palaeoclimatology, Palaeoecology (Special Issue): 192.

Millor, J., M. Pham-Delegue, J.-L. Deneubourg, and S. Camazine. 1999. "Selforganized defensive behavior in honeybees." Proceedings of the National Academy of Sciences USA 96: 12611-12615.

Niklas, K. 1999. "Evolutionary walks through a land plant morphospace." Journal of Experimental Botany 50: 39-52.

Parunak, H. D. 1997. “'Go to the ant': Engineering principles from natural multi-agent systems.” Annals of Operations Research 75: 69-101.

Pittendrigh, C. S. 1958. “Adaptation, natural selection and behavior.” In A. Roe and G. G. Simpson, eds., Behavior and evolution. New Haven: Yale University Press.

Poincaré, H. 1905. La science et l'hypothèse. Paris: Flammarion.

Pratt, S. C., E. B. Mallon, D. J. T. Sumpter, and N. R. Franks. 2002. "Quorum sensing, recruitment, and collective decision-making during colony emigration by the ant Leptothorax albipennis." Behavioral Ecology and Sociobiology 52: 117-127.

Pratt, S. C., D. J. T. Sumpter, E. B. Mallon, and N. R. Franks. 2005. “An agent-based model of collective nest choice by the ant Temnothorax albipennis." Animal Behaviour 70: 1023-1036. 
Ray, T. S. 1994. "An evolutionary approach to synthetic biology: Zen and the art of creating life." Artificial Life 1: 179-210.

Roces, F. 2002. "Individual complexity and self-organization in foraging by leaf-cutting ants." Biological Bulletin 202: 306-313.

Scheiner, R., J. Erber, and R. E. Page. 1999. "Tactile learning and the individual evaluation of the reward in honey bees (Apis mellifera L.)." Journal of Comparative Physiology A 185: 1-10.

Schmid-Hempel, P., A. Kacelnik, and A. L. Houston. 1985. "Honeybees maximize efficiency by not filling their crop." Behavioral Ecology and Sociobiology 17: 61-66.

Schneirla, T. C. 1971. Army ants: A study in social organization. San Francisco: Freeman.

Seeley, T. D. 1998. "Thoughts on information and integration in honey bee colonies." Apidologie 29: 67-80

Seeley, T. D., and P. K. Visscher. 2004. "Quorum sensing during nest-site selection by honeybee swarms." Behavioral Ecology and Sociobiology 56: 594-601.

Sendova Franks, A. B., and N. R. Franks. 1999. "Self-assembly, self-organization and division of labour." Philosophical Transactions of the Royal Society of London: Biological Science 354: 1395-1405.

Strogatz, S. 2004. "The physics of crowds." Nature 428: 367-368.

Theraulaz, G., E. Bonabeau, S. C. Nicolis, R. V. Sole, V. Fourcassie, S. Blanco, R. Fournier, J. L. Joly, P. Fernandez, A. Grimal, P. Dalle, and J.-L. Deneubourg. 2002. "Spatial patterns in ant colonies." Proceedings of the National Academy of Sciences USA 99: 9645-9649.

Theraulaz, G., E. Bonabeau, C. Sauwens, J.-L. Deneubourg, A. Lioni, F. Libert, L. Passera, and R. Solé. 2001. "Model of droplet dynamics in the argentine ant Linepithema humile (Mayr)." Bulletin of Mathematical Biology 63: 1079-1093.

Varju, D., and J. Núñez. 1993. "Energy balance versus information exchange in foraging honeybees." Journal of Comparative Physiology 172: 257-261.

Watmough, J., and S. Camazine. 1995. "Self-organized thermoregulation of honeybee clusters." Journal of Theoretical Biology 176: 391-402.

Weidenmüller, A. 2004. "The control of nest climate in bumblebee (Bombus terrestris) colonies: Interindividual variability and self reinforcement in fanning response." Behavioral Ecology 15: 120-128.

Weiss, G. 1999. "Multiagent systems: A modern approach to distributed artificial intelligence." Cambridge: MIT Press.

Wilson, E. O. 1971. The insect societies. Cambridge: Belknap Press. 